\title{
REFLEXÕES SOBRE A EXTENSÃO UNIVERSITÁRIA E A PARTICIPAÇÃO DA PSICOLOGIA NUM PROGRAMA DE PREVENÇÃO AO ABUSO DE ÁLCOOL E OUTRAS DROGAS
} Araci Asnelli da Luz
Emerson Luiz Peres

\begin{abstract}
RESUMO
A extensão universitária vem a cada dia ocupando seu espaço como atividade acadêmica capaz de produzir conhecimento a partir da interação entre o conhecimento científico e o conhecimento popular nas ações comunitárias. A postura interdisciplinar que dá suporte ao encaminhamento teórico metodológico do Programa de Extensão Universitária "Prevenção ao Abuso de Álcool e Uso de Outras Drogas" permite, neste artigo, refletir sobre a importância da participação do profissional da Psicologia como membro de uma equipe multiprofissional que pensa a prevenção primária como função educadora e de cidadania para a construção coletiva de um conceito e uma
\end{abstract}

Professora Adjunta do Departamento de Teoria e Prática do Ensino do Setor de Educação e Coordenadora do Programa de Extensão Universitária "Prevenção ao Abuso de Álcool e Uso de Outras Drogas".

** Psicólogo formado pela UFPR e Bolsista de Extensão do Programa "Prevenção ao Abuso de Álcool e Uso de Outras Drogas" no ano de 1996.

Interação, Curitiba, v. 1, p. 179-192, jan./dez. 1997 
cultura de saúde mental. Reforça, com isso, a necessária ampliação da sala de aula para os espaços comunitários, na qual o acadêmico em formação pode experienciar saberes teóricos e metodológicos enriquecedores para sua adequada formação, pela reflexão compartilhada com outros acadêmicos e profissionais de distintas áreas do conhecimento.

Refletir hoje sobre a extensão universitária é trazer à tona a questão do conhecimento. Considerada indissociável da pesquisa e do ensino, a extensão parece, no entanto, "ter sido colocada na prateleira dos fundos das Universidades" (FARIA in: BAIBICH e ARCO-VERDE, 1996). Nas Universidades Federais, a extensão universitária tem procurado modificar esse quadro adotando uma política de extensão que procura aproximar o saber científico de realidades múltiplas pelo compromisso de enfrentar o desconhecido, sem medo, com ousadia e sem improvisos, pela ação planejada e organizada em cursos, projetos, programas, eventos e ações complementares, nos quais tudo o que propõe a coordenação só o faz em parcerias pertinentes, ricas, acolhedoras e que se viabilizam pela participação desejosa, criativa, comprometida de acadêmicos bolsistas e voluntários, professores, funcionários e comunidade, exercendo seus direitos de cidadania.

No entanto, não se pode incorrer no risco da onipotência. A extensão é uma forma de construção de saberes novos pelo compartilhar do conhecimento científico com o conhecimento popular. Para que isso se efetue com qualidade, é preciso ter em mente o compromisso com a totalidade do conhecimento e, nas instituições de ensino superior, esta tem sido uma questão crucial. A estrutura departamentalizada e a competição velada pelos poucos recursos para o ensino, a pesquisa e a extensão têm impedido ou mesmo "travestido" a prática interdisciplinar, pela formação de 
grupos multiprofissionais, mas que continuam mantendo o monólogo do saber fragmentado das especialidades.

THOMPSON (1990) ao organizar a obra Gaia: uma teoria do conhecimento, retomando a formulação da hipótese Gaia ${ }^{1}$, de LOVELOCK (1986), enquanto modelo para uma dinâmica planetária e celular, ao reunir especialistas de diferentes áreas e correntes do conhecimento para um dos encontros da Lindisfarne Fellows, USA, assim se refere:

Agora eu gostaria que alçássemos vôo para um nível mais alto, e visualizássemos esse cenário intelectual, como a lente de uma câmera Landsat. Poderemos ver que todas essas correntes fazem parte de um mesmo lençol d'água, e todas estão convergindo para alimentar um único lago. Vejo esse lago como uma metáfora para uma nova comunidade, uma nova ecologia do conhecimento. À medida que essas diferentes correntes de pensamento começarem a se interligar num ecossistema mais amplo, começaremos a deixar a atuação particularizada da pesquisa e da inovação científicas para uma idéia diferente, que não será apenas a de uma nova descoberta ou uma nova teoria, mas de uma nova cultura planetária (p. 12).

É esta a visão que se quer ressaltar como necessária para a extensão universitária e, no contexto da interdisciplinaridade enfatizada neste artigo, reconhece-se a impossibilidade de áreas do saber isoladas responderem com a qualidade e a totalidade do conhecimento que um programa de prevenção ao uso de drogas exige.

FREIRE, in: NOGUEIRA (1994), afirma:

Metáfora que apresenta a Terra como um grande Ser Vivo, o único de sua espécie, exigindo dos homens um novo olhar sobre a vida na Terra. O termo Gaia, em sua origem grega, significa "mãe natureza", denominando o planeta enquanto ser vivo. 
A inter (ou trans) disciplinaridade é demanda da Natureza e da Realidade do Mundo. É como se ela dissesse: vocês, Humanos, podem conhecer-me, mas, para ajudá-los, eu vou logo dizendo que só me conhecerão com a condição de correlacionarem dialogicamente as múltiplas partes ou tendências que são necessárias a vocês.

É assim que se visualiza o compromisso com a construção do conhecimento, uma construção coletiva, a partir de saberes individuais que permitem a tecitura da rede do conhecimento voltada para a totalidade. A interdisciplinaridade, então, enquanto postura, permite o diálogo entre as diferentes áreas do conhecimento humano.

Ao nos referirmos a um programa de prevenção ao abuso de álcool e outras drogas, essa postura interdisciplinar deve ser ressaltada. Há muito a prevenção deixou de ser uma questão apenas médica (tratamento das conseqüências clínicas) ou jurídica (legalidade ou ilegalidade), para assumir uma postura social abrangente. O uso e o abuso de drogas, aqui referindo-se ao conjunto de substâncias psicoativas, é sobretudo uma questão de conduta humana que é ao mesmo tempo biológica, sociocultural e psicológica. Para KLUCKHOLM et al., in: BRASIL. MEC (1994, p. 14), todo homem é, sob certos aspectos, "biologicamente como todos os outros homens, culturalmente como alguns homens e psicologicamente como nenhum outro homem".

É esta especificidade da Psicologia que se quer ressaltar e refletir neste artigo.

Passa-se agora a algumas considerações acerca das possíveis contribuições teórico-práticas do profissional de Psicologia, sempre dentro de um contexto interdisciplinar, para a realização de um trabalho de Prevenção em Saúde Mental, como é o caso do Programa em Prevenção ao Abuso de Álcool e Uso de Outras Drogas da UFPR.

BLEGER (1976) escreve que: 
(...) el psicólogo interviene absolutamente en todo lo que incluye o implica seres humanos, para la protección de todo lo que concierne a los factores psicológicos de la vida, en sus múltiples manifestaciones: se interesa, en toda su amplitud, por la asimilación e integración de experiencias en un aprendizaje adecuado con plena satisfaccion de todos las necessidades psicológicas ${ }^{2}$.

Ele ainda indica que os tipos de situações ou problemáticas em que o.psicólogo deve intervir podem ser agrupadas da seguinte forma: 1) momentos ou períodos do desenvolvimento ou de evolução normal (gravidez, parto, amamentação, infância, puberdade, juventude, madureza, idade crítica, velhice); 2) momentos de mudança ou de crise; 3) situações de tensão normal ou anormal nas relações humanas (família, escola, trabalho, etc.); 4) organização e dinâmica de instituições sociais; 5) problemas que criam ansiedade em momentos ou períodos mais específico da vida (sexualidade, orientação sexual, casamento, etc.); 6) situações altamente significativas que requerem informação, educação ou direção. Assim, se o trabalho de prevenção, e mais especificamente o de prevenção ao abuso de drogas, está relacionado a todas essas situações de vida e o psicólogo tem seu campo de trabalho atrelado a tudo que se relaciona às relações humanas, é ele , portanto, um profissional de quem não se pode prescindir num programa que leve a sério a prevenção, uma vez que esse trabalho deve ter como ponto central o sujeito e suas relações com o outro e com o seu meio.

Em se falando especificamente de Saúde Mental, é BLEGER (1976), também, quem cita os "cinco objetivos da higiene mental" que se foram construindo historicamente: a terapêutica

2 (...) o psicólogo intervem absolutamente em tudo o que inclui ou implica seres humanos, para a proteção de tudo o que concerne aos fatores psicológicos da vida, em suas múltiplas manisfestações: se interessa, em toda a sua amplitude, pela assimilação e integração de experiências numa aprendizagem adequada, com plena satisfação de todas as necessidades psicológicas". (BLEGER, 1976) 
(no sentido de modificar a assistência psiquiátrica, levando a condições mais humanas); o diagnóstico precoce (possibilitando uma maior taxa de cura e uma diminuição dos sofrimentos e de tempo de internação); a reabilitação (no sentido de reintegração à vida social do paciente já curado - com ou sem seqüelas - ou daquele por quem a medicina curativa não pôde fazer nada); a profilaxia ou prevenção dos problemas mentais (atuando antes de sua aparição, evitando-as) e, por último, e talvez mais importante, a promoção da saúde (na qual não interessa somente a ausência de enfermidades, mas o desenvolvimento pleno dos indivíduos e da comunidade total, procurando, inclusive, diminuir ou eliminar situação de risco).

Dentro desse contexto, o autor define a importância do papel do psicólogo clínico para a higiene mental, especificando o ramo que chama de "psicohigiene" (sic), que pode ser traduzido pelos esforços realizados no sentido de promover um melhor nível de saúde da população, de melhores condições de vida, e "se o denomina así, no porque se busque la salud psíquica (lo cual sería un absurdo), sino porque se actua fundamentalmente sobre el nivel psicológico de los fenómenos humanos, con métodos y técnicas procedentes del campo de la psicología y la psicología social" (Id. Ibid. $)^{3}$. Ou seja, é uma proposta que se afasta do modelo clínico tradicional dos serviços de Psicologia, na qual prevalece uma concepção curativa que postula um tratamento individual como solução aos problemas do indivíduo, quando o quadro "doentio" já está instalado, elitizando e encarecendo o tratamento; e, embasada numa visão preventiva, busca pensar a Psicologia dentro de um quadro mais geral nos serviços de saúde e educação, dando espaço ao trabalho em equipe multidisciplinar e a modelos alternativos que possam tratar a questão da saúde mental de forma

\footnotetext{
Assim se o denomina não porque se busque a saúde psíquica (o que seria um absurdo), mas sim porque se age fundamentalmente sobre o nível psicológico dos fenômenos humanos, com métodos e técnicas procedentes do campo da psicologia e da psicologia social.
} 
ampla, mais adequada e acessível à população, dando ênfase à promoção da saúde mental e não mais à cura (sem necessariamente desprezar recursos curativos quando necessário), prática esta que reafirma o direito de ser feliz e saudável (direito à saúde mental) como uma faceta inerente à verdadeira cidadania.

Essa visão se aproxima e reforça a concepção do Sistema Único de Saúde (SUS) de um sistema hierarquizado e regionalizado, sugerido pela Organização Mundial de Saúde (OMS) e pela Organização Pan-americana de Saúde (OPAS), onde se busca a simplificação da tecnologia médica, adaptando-se a realidade específica de saúde da população através dos diferentes níveis de atenção à saúde: nível primário, secundário e terciário. Essa concepção de sistema de saúde estabelece uma estratégia preventiva e tem por objetivo, também, promover uma participação ativa da população nessas ações.

É CAPLAN (1966) quem traz essa concepção para a área de saúde mental em seu livro Princípios de Psiquiatria Preventiva, no qual postula as concepções de prevenção primária, prevenção secundária e prevenção terciária em saúde mental.

A contribuição do profissional de psicologia pode se dar amplamente em todas essas áreas da prevenção, que, como sabemos, não são isoladas entre si, mas estão interligadas pelo compromisso com a promoção da saúde pública. Nessa área, mais que nunca, o papel do psicólogo cresce à medida que ele está bem entrosado numa equipe multiprofissional e o seu trabalho faz parte de uma ação integrada, planejada e construída coletivamente. Aqui já aparece uma possibilidade de intervenção do psicólogo.

Agora, ainda que sucintamente, tecem-se comentários sobre algumas possibilidades de intervenção do profissional de psicologia nesses diferentes níveis, a começar com a prevenção terciária, associada a hospitais e centros de reabilitação, aptos a desenvolverem os serviços mais complexos como, por exemplo, o interna- 
mento de dependentes químicos para um tratamento de desintoxicação e para início de abstinência. Nesse nível, a intervenção do psicólogo se dá, basicamente, através do psicodiagnóstico e da psicoterapia individual ou grupal, e sua atuação deve ser, também, no sentido de uma maior humanização no tratamento hospitalar, acompanhando, junto aos demais profissionais, as reflexões acerca de um aproveitamento maior ou mais racional dos hospitais psiquiátricos, promovendo intervenções mais precoces e mais breves, sobre o funcionamento de hospitais-dias e a incorporação de serviços psiquiátricos nos hospitais gerais.

Em nível de prevenção secundária, que se refere ao atendimento ambulatorial (ambulatórios ou centros de saúde regionais, e mesmo em nível de consultórios particulares), onde se fornecem serviços que demandam ainda algum nível de especialização, o psicólogo também terá uma atuação mais clínica, possibilitando a avaliação psicológica de casos e podendo trabalhar tanto com a psicoterapia individual como em grupo. Aqui, a sua integração com a equipe médica também se faz importante pois "a integração de serviços adequados de saúde mental aos cuidados médicos básicos pode (...) permitir a explicitação da demanda por cuidados em Psicologia antes da manifestação aguda dos quadros que justificariam a internação psiquiátrica" (VASCONCELOS, 1987). Assim, as demandas por cuidados específicos da Psicologia que emergem implicitamente através de pedidos de cuidados médicos podem encontrar acolhimento e serem tratadas em nível ambulatorial mesmo, o que possibilita diagnóstico e tratamento mais precoce do problema (no caso de abuso de drogas, por exemplo, antes que a dependência tenha se instalado completamente e atingido os diferentes setores de sua vida); e isso pode ocorrer quando a equipe de saúde também possui essa "escuta", que é desenvolvida muito em função da convivência com o profissional psi.

$\mathrm{E}$, finalmente, é na prevenção primária, de caráter mais educativo e comunitário, que o psicólogo (e qualquer outro profis- 
sional ligado à saúde e/ou educação) possui as mais diferente alternativas de atuação, tão grande é esse campo conceitual e prático. É aqui que deve ser depositada toda a energia para o sucesso de qualquer programa de prevenção (em lugar de campanha), pois é em decorrência do sucesso ou do fracasso nesse nível de atuação que os demais níveis de atenção à saúde vão se estruturar. É o nível de prevenção, propriamente dita.

$\mathrm{Na}$ prevenção primária, mais do que em qualquer outro nível, é que se trabalha com a noção de promoção de saúde, no qual o Programa de Prevenção ao Abuso de Álcool e outras Drogas $^{4}$ está centrado. Se o objetivo deste programa, em verdade, é favorecer a criação de uma cultura de prevenção em nosso meio (iniciando pelo meio universitário e se expandindo à comunidade), a Psicologia tem muito a colaborar nesse sentido, em sua concepção teórica e metodológica.

Primeiramente, podemos falar que uma cultura de prevenção não se estabelece se não houver muito desejo, prazer, vontade, motivação e participação da comunidade e da equipe técnica envolvida. Todos esses conceitos são objetos de estudo e observação da Psicologia em suas diferentes formas de atuação e linhas teóricas; o profissional de psicologia deve estar capacitado para fazer uma leitura desses fenômenos e, se necessário, atuar de modo a favorecer o estabelecimento de uma cultura de valorização da vida, de prevenção. É nesse sentido que o profissional de Psicologia em formação atua, enquanto bolsista deste Programa de Extensão, ao compor uma equipe interdisciplinar na UFPR; assim, além de participar da equipe do ambulatório de alcoolismo do Hospital de Clínicas, que está ligado ao Programa (prevenção secundária), ele participa da organização e realização de eventos, tais como a Semana Estadual de Prevenção, e realiza encontros de sensibilização com crianças e grupos de adolescentes (prevenção primária).

4 Vinculado à Pró-Reitoria de Recursos Humanos e Assuntos Estudantis (PRHAE) e à PróReitoria de Extensão e Cultura (PROEC) da Universidade Federal do Paraná (UFPR). 
A prevenção, sem dúvida alguma, é papel do educador. No entanto, a educação é um processo construído nas interações entre seres sociais e precisa ser vista não só no seu aspecto mais formal (Educação Formal), mas também no seu aspecto informal, através das relações familiares e comunitárias de todo indivíduo, nas diferentes etapas da sua vida (com atenção especial para a criança e o adolescente). É aí que entra o papel do psicólogo como educador preocupado com a prevenção, por ser um profissional que possui um saber teórico e um domínio de técnicas que dizem respeito às relações humanas, familiares, de trabalho, escolares e sociais em geral. Se a questão da prevenção ao abuso de drogas não deve ser focada nas drogas, nem só no ambiente, nem só no indivíduo usuário de drogas, e sim na dinâmica relaciona) estabelecida por este indivíduo num determinado contexto, então, o psicólogo é um dos profissionais mais bem preparados para promover esta prevenção. Ressalta-se que promover a prevenção não é necessariamente fazer prevenção, pois, a prevenção deve se dar no dia-a-dia. Portanto, ninguém melhor do que a pessoa que convive com a criança para preveni-la dos problemas que possam surgir em seu futuro, ou seja, seus pais, parentes próximos e professores. Assim, a equipe do Programa de Prevenção da UFPR tenta propiciar uma instrumentalização a essas partes, no sentido da prevenção em seu cotidiano, promovendo cursos e treinamentos para profissionais, professores, agentes de saúde e a comunidade em geral, dos quais o psicólogo participa desde a sua concepção até a sua execução, com sua contribuição específica.

O profissional de Psicologia, no entanto, pode dar sua contribuição trabalhando os temas que dizem respeito a sua experiência profissional e seu conhecimento específico como, por exemplo, temas e técnicas que apontam para aspectos relacionados ao uso e abuso de álcool e outras drogas, a sexualidade, relações humanas, liderança, dinâmica dos grupos e outros que se fazem importantes para propiciar uma reflexão e uma vivência favore- 
cendo a sensibilização do indivíduo. Ele pode trabalhar com grupos de crianças, adolescentes, pais, educadores, profissionais da saúde, grupos de empresas, no sentido de promover uma formação ou algum treinamento em atividade de prevenção e de promoção da saúde integral do indivíduo.

Assim, o psicólogo também atuaria como mais um agente provocador de um constante pensar crítico sobre a prática da prevenção. "É possível, dentro de um corpo de conhecimentos, passar por uma revisão crítica que assinale as limitações e potencialidades de cada proposta metodológica, e possibilitar uma reapropriação dos métodos e técnicas para outro contexto e objetivos sociais" (VASCONCELOS, 1987). Por exemplo, podendo-se aplicar recursos da bioenergética, expressão corporal e/ou psicodrama, em programas de prevenção em questões de educação sexual e consumo de álcool e outras drogas com adolescentes, ou utilizar técnicas de desenvolvimento da comunicação interpessoal, num curso de capacitação com professores de $1^{\circ}$ e $2^{\circ}$ Graus.

É necessário reafirmar que essas práticas não podem vir de uma forma isolada e devem ser construídas levando em consideração a experiência pessoal e técnica do profissional, bem como a sua inserção numa dada realidade, envolvendo ativamente a comunidade alvo. Daí vem a necessidade da sistematização das experiências em prevenção para se criar criticamente uma metodologia própria de trabalho em saúde mental que favoreça a participação social.

Entendendo a participação popular como indispensável para o funcionamento de todo o sistema de saúde e educação, o psicólogo social que apresenta uma abordagem em trabalho comunitário é bem-vindo a qualquer atenção preventiva que pretenda suscitar uma ação planejada e participativa.

A respeito da atuação dos profissionais da área de atendimento à dependência química SOARES (1993) afirma que: 
suas ações e concepções terapêuticas também estão necessariamente permeadas de crenças, valores e pressupostos, dado que noções como alcoolismo e drogadição, são, como sabemos, atravessadas pelo crivo das mediações culturais e não se limitam a simples fenômenos orgânicos, ganhando sentido e existência em contextos sociais específicos.

Portanto, não se pode esquecer a possibilidade de intervenção do psicólogo como membro de uma equipe interdisciplinar, remetendo-a a uma reflexão individual e coletiva sobre o trabalho realizado, a postura profissional e pessoal sobre o serviço prestado e sobre o lugar ocupado por cada um neste contexto interdisciplinar; favorecendo um clima de respeito e escuta mútua. SCHUCKIT (1991) chama a atenção para as dificuldades associadas ao uso e abuso de álcool e outras substâncias psicoativas que ocorrem entre os profissionais de saúde e estudantes, e sugere que se considere a necessidade do desenvolvimento de estratégias de prevenção cuidadosas para os estudantes e profissionais no sistema de saúde.

No entanto, o trabalho nessa área não é nada fácil. Se no trabalho de tratamento à dependência química o índice de recuperação para muitos profissionais não é nada animador, no trabalho em prevenção, propriamente dito, também se encontram alguns percalços e frustrações. Além das já apontadas, destacamos aqui outras dificuldades que afetam os programas de prevenção, a começar com as limitações advindas da falta de apoio e recursos a esses programas, uma vez que normalmente seus resultados apenas são visíveis a médio e longo prazos e ainda se dá, em nossa cultura (e em nosso meio político), uma importância maior ao alcance de resultados imediatos do que a investimentos em educação básica (em seu sentido amplo).

A efetivação do trabalho interdisciplinar se apresenta como outra dificuldade nos programas de prevenção; nessa área os 
problemas surgem, principalmente, devido à dificuldade de interrelação dos diferentes profissionais de diferentes áreas (que, inclusive, possuem diferentes experiências de vida e postura pessoal). Essa dificuldade de trabalhar em equipe e a característica falta de noção do papel e do lugar de cada um no trabalho (inclusive dos próprios), em grande parte, é decorrente de uma formação que não contempla o trabalho coletivo e social, ou seja, a prevenção.

Considerando essas colocações a respeito das possíveis contribuições da Psicologia e do profissional da área em estratégia de prevenção, salienta-se um problema fundamental: a formação desse profissional. É claro que para uma atuação próxima do que foi aqui exposto, isto implicaria uma profunda mudança na formação atual dos psicólogos, aproximando-os de uma atuação comunitária, de forma a garantir uma formação geral que abra possibilidades para se atuar tanto na área de saúde (clínica) como nas áreas escolar, educacional, organizacional e social.

$\mathrm{Na}$ formação, além da necessidade dos métodos e técnicas de trabalho estarem mais apropriados à realidade psicossocial, estes devem ser dirigidos principalmente às atividades educativas e preventivas e não apenas clínicas e psicoterapêuticas, como normalmente se dá hoje. "Outro elemento que não pode faltar à formação deste profissíonal será também o estudo de estratégias em saúde pública, bem como elementos de administração desses serviços" (VASCONCE LOS, 1987).

Assim, essa formação deverá ser eminentemente prática, o que pode ser destacado nesta parceria extensão/trabalho interdisciplinar, que permite a expansão da sala de aula em direção ao espaço comunitário, numa troca de experiências entre diversas áreas de saber em diferentes formas de atuação, privilegiando a postura ética como motor para o crescimento individual e coletivos, entre outros. 


\section{REFERÊNCIAS BIBLIOGRÁFICAS}

1 BAIBICH, T. M.; ARCO-VERDE, Y. E. de S. Avaliação da extensão universitária. Curitiba : Ed. da UFPR, 1996.

2 BLEGER, J. Psicohigiene y Psicologia Institucional. Buenos Aires : Paidós, 1976.

3 BRASIL. Ministério da Educação e do Desporto. Secretaria de Projetos Educacionais Especiais. Diretrizes para uma política educacional em sexualidade. Brasília: MEC/ SEPESPE, 1994.

4 CAPLAN, G. Princípios de psiquiatria preventiva. Buenos Aires : Paidós, 1966.

5 LOVELOOCK, J. Gaia: um olhar sobre a vida na Terra. Lisboa : Edições 70, 1987.

6 NOGUEIRA, A. (Org.). Contribuições da interdisciplinaridade para a ciência, para a educação, para o trabalho sindical. Petrópolis : Vozes, 1994.

7 SCHUCKIT, M. Abuso de álcool e drogas. Uma orientação clínica ao diagnóstico e tratamento. Porto Alegre : Artes Médicas, 1991.

8 SOARES, B. M. Alcoólicos Anônimos: uma mensagem na garrafa lançada ao mar. In: INEM, C. L.; ACSELRAD, C. Drogas: uma visão contemporânea. Rio de Janeiro : Imago, 1993.

9 THOMPSON, W. I. (Org.). Gaia: uma teoria do conhecimento. São Paulo : Gaia, 1990.

10 VASCONCELOS, E. M. O que é psicologia comunitária. São Paulo : Brasiliense, 1987. 